\title{
Severe respiratory failure requiring ICU admission in bone marrow transplant recipients
}

\author{
D. Gruson*, G. Hilbert*, L. Portel*, J.M. Boiron ${ }^{+}$, C.M. Bebear", F. Vargas*, Ch. Bebear", \\ J. Reiffers ${ }^{+}$, G. Gbikpi-Benissan*, J.P. Cardinaud*
}

Severe respiratory failure requiring ICU admission in bone marrow transplant recipients. D. Gruson, G. Hilbert, L. Portel, J.M. Boiron, C.M. Bebear, F. Vargas, Ch. Bebear, J. Reiffers, G. Gbikpi-Benissan, J.P. Cardinaud. (C)ES Journals Ltd 1999.

ABSTRACT: Two groups of bone marrow transplant (BMT) recipients with febrile noncardiogenic respiratory failure requiring intensive care unit (ICU) admission, in the early phase of bone marrow transplantation were compared: those who had proven infectious pneumonia and those in whom bronchoalveolar lavage (BAL) failed to establish a diagnosis.

Thirty-eight consecutive neutropenic BMT recipients admitted to an ICU with febrile noncardiogenic respiratory failure were enrolled. All of them underwent a BAL with viral, fungal, bacterial, and histopathological examinations. Lung biopsies were performed in nonsurviving patients in order to compare with BAL results. Haematological, biological, respiratory failure and other organ failure parameters, infectious results, outcome, and lung biopsy results were evaluated.

BAL allowed an infectious diagnosis to be established in 16 BMT recipients. No aetiology was proven in 22 patients. Without a significant difference in respiratory failure parameters on ICU admission, noninvasive continuous positive airway pressure ventilation, which was given to 11 patients in each group, was significantly more successful in patients with proven infectious pneumonia (6 of 11 versus 0 of 11 patients) and enabled endotracheal intubation to be avoided in significantly more patients with infectious disease (10 of 16 versus 22 of 22 patients). The evolution of patients without diagnosis was significantly different with more frequent renal failure, hepatic failure, and death (20 of 22 versus 9 of 16 patients). Post mortem biopsies confirmed the absence of micro-organisms, but endothelial damage and fibrosis was found in 14 of the 22 patients.

In conclusion, in the early phase of bone marrow transplantation the recipients without proven aetiology of pneumonia have a worse outcome than grafted patients with proven infectiuous pneumonia.

Eur Respir J 1999; 13: 883-887.

Bone marrow transplantation has been used successfully since 1968 . Of its complications $40-60 \%$ have a pulmonary origin and it is estimated that $>30 \%$ of bone marrow transplantation-related deaths are caused by respiratory complications [1]. Prior studies have demonstrated that bronchoalveolar lavage (BAL) may provide a diagnosis in $50-80 \%$ of bone marrow transplant (BMT) patients with pulmonary infiltrates $[2,3]$. Infections are a frequent cause of these infiltrates. The most commonly identified pathogens are bacteria, cytomegalovirus (CMV), Aspergillus fumigatus, Pneumocystis carinii, and herpes simplex virus. However, no infectious aetiology is identified in $30-45 \%$ of cases with nonbacterial pneumonia [1, 4]. Suggested aetiologies for these apparently noninfectious lung injuries after a BMT have included chemoradiation damage, graftversus-host reaction, diffuse alveolar haemorrhage, and pulmonary vascular abnormalities [5-7]. Pulmonary infiltrates developing in the early phase of a BMT continue to pose considerable diagnostic problems, especially when these patients require intensive care unit (ICU) admission, because the aetiology of this severe failure remains un-
*Intensive Care Unit, ${ }^{+}$Dept of Hematology and "Laboratory of Bacteriology, University Hospital of Bordeaux, France.

Correspondence: D. Gruson

Réanimation médicale $\mathrm{B}$

Hopital Pellegrin

Place Amélie Raba Léon

33076 Bordeaux

France

Fax: 33556796122

Keywords: Bone marrow transplantation endothelial damage

engraftment

intensive care unit

respiratory failure

Received: January 151998

Accepted after revision November 261998 certain. The clinical course of consecutive neutropenic BMT recipients who were admitted to an ICU for febrile respiratory failure, in the early phase of transplantation have been analysed. In particular, two groups of BMT recipients were compared according to whether or not they had proven infectious pneumonia.

\section{Patients and methods}

Between November 1993 and December 1997, all consecutive BMT patients, who were admitted to an ICU for respiratory failure with noncardiogenic oedema, were enrolled in the study. The transplant procedure was performed following the technique reported by THOMAs et al. [8]. The admission to an ICU was in the early phase of transplantation. In the ICU, the haematological malignancy history, the type of bone marrow transplantation, the occurrence of graft-versus-host disease (GVHD), the clinical signs of veno-occlusive disease, the clinical and biological signs of respiratory failure and other organ failure (defined 
by one of the following criteria in each category: hepatic, total bilirubin level $>3 \mathrm{mg} \cdot \mathrm{dL}^{-1}$, renal, urinary output $<600$ $\mathrm{mL} \cdot 24 \mathrm{~h}^{-1}$, and necessity of dialysis or ultrafiltration) were evaluated. The absolute absence of cardiac failure was based on clinical examination, chest radiography and echocardiography. Patients with a cardiac cause of respiratory failure were excluded. Most patients underwent fibreoptic bronchoscopy on admission to the ICU. The contra-indications to bronchoscopy included abnormal results of coagulation tests that could not be corrected with fresh frozen plasma, and a platelet count $<50 \times 10^{3} \cdot \mathrm{mm}^{-3}$ posttransfusion. Clinically unstable patients who did not undergo BAL were excluded. The presence of a pulmonary infection was defined by the presence of at least $10^{4}$ colony forming unit $\cdot \mathrm{mL}^{-1}$ bacteria in the bacteriological quantitative culture of BAL fluid. A direct fluorescent antibody assay for $P$. carinii and mycobacterial studies were also performed. BAL fluid was sent for histopathological examination. CMV was considered to be a pathogen if grown via shell culture from the BAL sample or if inclusion bodies were present on histopathological evaluation. $P$. carinii pneumonia was diagnosed by a positive direct fluorescence antibody or Gomori methynamine silver stain. Fungal organisms were identified by culture fungal smear using calcofluor white stain of BAL or histological examination.

Noninvasive ventilation was used in a sequential mode following the methods that were published recently $[9,10]$. The sequential mode used consisted of determining periods of ventilation and alternating it with periods of spontaneous breathing. The ventilation periods lasted at least 30 min, and were performed at very regular intervals.

The supportive care of neutropenia and the treatment of GVHD or veno-occlusive disease were followed in the ICU. A diagnosis of veno-occlusive disease was suspected if patients fulfilled two of the criteria of MCDONALD et al. $[11,12]$ : a $>2.0 \%$ weight gain with or without ascites, hepatomegaly or right upper quadrant pain, and bilirubin $>2.0 \mathrm{mg} \cdot \mathrm{dL}^{-1}$. A proven veno-occlusive disease diagnosis was defined by compatible liver biopsies. In the ICU, BMT recipients were divided into two groups: those with febrile noncardiogenic respiratory failure with proven infectious pneumonia and those without infectious aetiology (sterile microbial cultures of BAL fluid and blood examinations).

When possible, post mortem lung biopsies were performed in patients without proven diagnosis of pulmonary failure. Post mortem biopsies were performed through an anterior thoracotomy. Three biopsy specimens from at least two involved lobes were taken in all cases. Standard histological, cytological and microbiological methods were used $[13,14]$.

\section{Statistical analysis}

Descriptive results are presented for continuous variables with their mean \pm SD. A Student's t-test and a Chisquared test were used for comparison of each parameter between the two defined groups. The significance level was set at $\mathrm{p}<0.05$.

\section{Results}

Thirty-eight BMT recipients were enrolled in the study. All patients were neutropenic (leukocyte count: $329 \pm 36$ cells $\left.\cdot \mathrm{mm}^{-3}\right)$. An infectious cause of respiratory failure was present in 16 patients. Bacteria were most frequently isolated, with primarily staphylococcal and pseudomonas species: staphylococcal species $(\mathrm{n}=5)$, pseudomonas species $(\mathrm{n}=3)$, streptococcal species $(\mathrm{n}=2)$, Proteus mirabilis $(\mathrm{n}=1)$, CMV $(n=3)$, herpes simplex virus $(n=1)$, candida species $(n=1)$, aspergillus $(n=2)$. In five patients, the development of a bacteraemia confirmed the infectious aetiology of pneumonia (staphylococcal species $(n=3)$, pseudomonas species $(n=1)$, streptococcal species $(n=1))$.

Twenty-two patients without documented infection were classified in the noninfection group. These BMT recipients received empiric antibiotherapy, which was on going despite the fact that no micro-organisms were isolated: cefepime $(n=5)$, piperacillin $(n=6)$, ceftazidime $(n=9)$, ceftriaxone $(n=1)$, cefotaxime $(n=1)$, spiramycin $(n=6)$, fluoroquinolones $(n=4)$, aminoglycosides $(n=8)$, vancomycin $(n=20)$, amphotericin $B(n=15)$, and fluconazole $(n=5)$, itraconazole $(\mathrm{n}=2)$.

There was no characteristic demographical difference between patients with or without proven infectious pneumonia (table 1). The type of transplant, the diagnosis and the disease phase of haematological malignancies were similar between the two groups of transplant recipients (tables 2 and 3). Among the allogeneic grafted patients without proven infection, the incidence of the combination of female donor with male recipient was higher (6 of 14) than in the other group with proven infectious pneumonia (1 of 10), but without a significant difference. The timespan between bone marrow transplantation and the admission to an ICU was not statistically different (table $4)$. At the time of ICU admission, lung injury score and arterial oxygen tension $\left(\mathrm{Pa}_{\mathrm{a}} \mathrm{O}_{2}\right)$ /inspiratory oxygen fraction $\left(F \mathrm{I}, \mathrm{O}_{2}\right)$ were not significantly different between the two groups [16]. Radiographic reports were comparable between the two groups. Infiltrates were described as diffuse (bilateral lobes of $\geq 2$ in number) in six patients in whom infectious pneumonia was diagnosed, and in 11 patients with no pulmonary failure diagnosis. Infiltrates were described as lobar (unilateral involving $\leq 2$ lobes) in 10 patients with infection and 11 patients without proven infectious pneumonia.

In 11 of the 22 patients without proven infection and in 11 of the 16 patients with infectious pneumonia, noninvasive ventilation support (continuous positive airway pressure; CPAP) was used. This technique was sucessful only in the cases of patients with documented pulmonary infection. Indeed, all 11 patients without proven infection were intubated. In six of the patients with infectious pneumonia, CPAP enabled mechanical ventilation to be avoided. This difference is significant $(\mathrm{p}=0.01)($ table 4$)$.

Table 1. - Mean \pm SD demographic parameters of bone marrow grafted recipients without a proven diagnosis of an infection $(n=22)$ and recipients with documented infectious pneumonia $(\mathrm{n}=16)$

\begin{tabular}{lcc}
\hline Parameters & $\begin{array}{c}\text { Noninfectious } \\
\text { group }\end{array}$ & $\begin{array}{c}\text { Infectious } \\
\text { pneumonia }\end{array}$ \\
\hline Age yrs & $34 \pm 8$ & $38 \pm 4$ \\
SAPS II & $50 \pm 10$ & $47 \pm 11$ \\
Male/female & $16 / 6$ & $10 / 6$ \\
\hline
\end{tabular}

SAPS II: Simplified Acute Physiology Score II [15]. 
Table 2. - Chemotherapy agents and types of transplant in the two groups of patients: with $(n=22)$ and without $(n=$ 16) proven infectious pneumonia

\begin{tabular}{lcc}
\hline & $\begin{array}{c}\text { Noninfectious } \\
\text { group }\end{array}$ & $\begin{array}{c}\text { Infectious } \\
\text { pneumonia }\end{array}$ \\
\hline Chemotherapy agent & & \\
Melphalan & 4 & 5 \\
Fractioned total body irradiation & 10 & 7 \\
Total body irradiation & 7 & 6 \\
Cyclophosphamide & 17 & 11 \\
Busulphan & 1 & 0 \\
BCNU & 3 & 2 \\
Etoposide & 3 & 2 \\
Cytosine arabinoside & 3 & 5 \\
Bone marrow transplant type & & \\
Autologous & 8 & 6 \\
Unrelated allogeneic & 2 & 0 \\
Related allogeneic & 12 & 10 \\
Donor-recipient sex & & \\
Male-male & 5 & 5 \\
Female-male & 6 & 2 \\
Male-female & 2 & 1 \\
Female-female & 1 & 2 \\
\hline BCNU: & & \\
\hline
\end{tabular}

BCNU: 1, 3-bis-(2-chloroethyl)-1-nitrosourea.

At the time of ICU admission and in accordance with the clinical criteria of McDonald et al. [11, 12], venoocclusive disease was suspected in eight patients in the noninfectious group and in two patients with proven infectious pneumonia (no significant difference). GVHD was suspected in eight patients in the noninfectious group (8 of 14 allogeneic BMT), with four of them having proven GVHD by cutaneous biopsies. In patients with infectious pneumonia, GVHD was suspected in four cases. One of these patients had a cutaneous rash and GVHD was revealed by skin biopsy. The treatment of acute GVHD of grade II or greater severity consisted of methylprednisolone $2 \mathrm{mg} \cdot \mathrm{kg}$ of body weight ${ }^{-1} i$.v. until a clinical response was observed. Two patients without proven infection and with acute GVHD had high doses of methylprednisolone,

Table 3. - Disease phase of the haematological malignancies and haematological diagnoses of patients with and without infectious pneumonia

\begin{tabular}{lcc}
\hline Parameters & $\begin{array}{c}\text { Noninfectious } \\
\text { group }\end{array}$ & $\begin{array}{c}\text { Infectious } \\
\text { pneumonia }\end{array}$ \\
\hline Haematological & & \\
malignancies & & \\
ANLL & 11 & 8 \\
ALL & 6 & 3 \\
CL & 2 & 1 \\
NHL & 2 & 0 \\
MM & 1 & 12 \\
Disease phase & 18 & 1 \\
CR & 2 & 3 \\
NCR & 1 & 0 \\
CP & 1 & \\
AP & & \\
\hline ANLL: & & \\
\hline
\end{tabular}

ANLL: acute non-lymphoblastic leukaemia; ALL: acute lymphoblastic leukaemia; CL: chronic leukaemia; NHL: nonHodgkin lymphoma; MM: multiple myeloma; CR: complete remission; NCR: noncomplete remission; CP: chronic phase; AP: accelerated or blastic phase.
Table 4. - Comparison of parameters of respiratory failure occurring in patients with and without proven infectious pneumonia and the characteristics of mechanical ventilation (MV) in the two groups

\begin{tabular}{lccc}
\hline Parameters & $\begin{array}{c}\text { Noninfectious } \\
\text { group } \\
(\mathrm{n}=22)\end{array}$ & $\begin{array}{c}\text { Infectious } \\
\text { pneumonia } \\
(\mathrm{n}=16)\end{array}$ & \\
\hline $\begin{array}{l}\text { Timespan ICU admission/ } \\
\quad \text { BMT days }\end{array}$ & $11 \pm 3.7$ & $11.5 \pm 3.5$ & $\mathrm{NS}$ \\
$\begin{array}{l}\text { Noninvasive ventilation } \mathrm{n} \\
\text { Noninvasive ventilation: }\end{array}$ & 11 & 11 & $\mathrm{NS}$ \\
$\quad$ failure n & 11 & 5 & 0.01 \\
$\begin{array}{l}\text { MV n } \\
\text { Mean PEEP with MV }\end{array}$ & 22 & 10 & 0.007 \\
$\quad$ cmH & 7 & 5 & NS \\
$\begin{array}{l}P a, \mathrm{O}_{2} / F \mathrm{I}, \mathrm{O}_{2} \\
\text { Lung injury score }\end{array}$ & $163 \pm 57$ & $184 \pm 53$ & $\mathrm{NS}$ \\
\hline
\end{tabular}

ICU: intensive care unit; BMT: bone marrow transplantation; PEEP: positive end-expiratory pressure (used in $\mathrm{MV}$ ); $\mathrm{Pa}, \mathrm{O}_{2}$ : arterial oxygen tension; $\mathrm{FI}_{1} \mathrm{O}_{2}$ : inspiratory oxygen fraction. Lung injury score as defined by MURRAY et al. [16].

5 and $7 \mathrm{mg} \cdot \mathrm{kg}$ of body weight ${ }^{-1} \cdot$ day $^{-1}$. These two patients survived.

Among the 24 allogeneic BMT patients, all received cyclosporine. At the time of ICU admission, there was no difference in creatinine values between the two groups. At the same time, only four patients without proven infection had oliguric renal failure and required dialysis. During the ICU hospitalization, most of patients in the noninfectious group presented with a multiple organ failure syndrome, including renal failure. Continuous venovenous filtration was necessary in 10 of these patients. This renal evolution was significantly different from that of patients with infectious pneumonia. In the group of patients with noninfectious pneumonia, the combination of severe respiratory failure with mental confusion was significantly higher than in the group of grafted recipients with infectious pneumonia $(\mathrm{p}=0.03)$.

The evolution of the disease in the ICU was fatal in $91 \%$ of patients without proven infection and $56 \%$ of patients with infectious pneumonia $(\mathrm{p}=0.03)$. In the group of $\mathrm{pa}-$ tients with a proven infection, nine patients did not survive. In these cases, the pathogenic micro-organisms were: $A$. fumigatus $(\mathrm{n}=2), \mathrm{CMV}(\mathrm{n}=3)$, staphylococcal species $(\mathrm{n}=$ $2)$, and pseudomonas species $(\mathrm{n}=2)$. All nonsurviving patients presented with a multiple organ failure syndrome. Post mortem lung biopsies were performed in 15 patients, who had no diagnosis with the BAL procedure. In 13 cases, histopathological examination revealed alveolar and endothelial damage, without a micro-organism or haematological malignancy relapse. In $69 \%$ of the cases, an accumulation of macrophages was observed in the alveolar spaces. Fibrinoproliferation was seen in eight examinations. In two other cases, a diagnosis could be established: alveolar haemorrhage and herpes simplex virus infection.

\section{Discussion}

Two groups of neutropenic BMT recipients admitted to an ICU for febrile noncardiogenic acute respiratory failure were compared. These groups were defined according to the cause of the acute respiratory distress, i.e. infectious or 
noninfectious. Noninvasive CPAP ventilation was significantly more successful and enabled endotracheal intubation to be avoided in patients with proven infectious pneumonia. In patients without established infectious pneumonia, the evolution was significantly different, with a higher incidence of renal failure, hepatic failure and death.

In order to analyse a difference between these two groups of BMT recipients, an arbitrary definition was necessary. Some BMT recipients could have been classified in the noninfectious group, but had severe nondocumented infectious pneumonia. The systematic use of empiric antibiotherapy could provoke false negative results in microbial examination of BAL fluid. In this severe neutropenic context and despite the fact that no microorganism was isolated, all empiric antimicrobial therapies were carried out. Post mortem lung biopsies were performed in 15 patients, who had no diagnosis with the BAL procedure. In 13 cases, histopathological examination revealed alveolar and endothelial damage, without microorganisms or haematological malignancy relapse. It was not therefore possible to establish a specific diagnosis. A proven diagnosis of infectious pneumonia was not established in some cases. These nonestablished diagnoses of infection may have resulted in the death of patients due to inappropriate therapy. But this situation was not the case for the majority of patients. Indeed, post mortem biopsies were negative in most of them.

Despite the same severity of acute lung injury $\left(\mathrm{Pa}, \mathrm{O}_{2} /\right.$ $F \mathrm{I}, \mathrm{O}_{2}$, Murray's score [16]), one group of patients presented with fatal multiple organ failure syndrome earlier. It was readily established that patients without a proven infectious diagnosis died more frequently (mortality rate: $91 \%$ ). This result corresponds to the published reports. In the study of Appelbaum et al. [17], pneumonia of neither bacterial nor fungal origin had a $70 \%$ case fatality rate. Overall mortality in BMT patients who required bronchoscopy was $61 \%$ in the study of DUNAGAN et al. [18]. In this study, mortality in BMT patients who required mechanical ventilation was $96 \%$ and mortality rate in patients in whom a microorganism was isolated was $52 \%$. In mechanically ventilated haematological patients, BRUNET et al. [19] reported an overall mortality rate of $86 \%$. In this study, among ventilated patients for pneumonitis, $81 \%$ died. In the study of Link et al. [20], among 51 episodes of pulmonary complications, $39 \%$ died. Mortality was higher in patients in early neutropenic phase after bone marrow transplantation. Among 16 neutropenic BMT recipients with pneumonitis, $50 \%$ died. In these 16 patients, eight had an infectious aetiology. In BMT recipients after mechanical ventilation, RUBENFIELD et al. [21] reported, with previous studies, a mortality rate of $95 \%$.

The established difference in survival between the two groups of BMT recipients was not explained by a higher multiorgan failure score in one group. Indeed, at the time of admission to ICU, no difference in hepatic or renal dysfunction was observed between the two groups.

CPAP was more effective in neutropenic patients with infectious pneumonia. Spontaneous ventilation with positive airway pressure is not described in great detail in the literature. In this study, CPAP enabled endotracheal intubation to be avoided. This point seems to be very important. Several studies have reported a great correlation of mechanical ventilation and mortality in neutropenic patients. More than $50 \%$ of the patients with proven in- fectious pneumonia were not intubated through CPAP and survived.

From necropsy, most of the patients without a diagnosis had nonspecific alveolar and endothelial injuries. The aetiology of the initial pulmonary failure and then of the multiple organ failure syndrome of these patients was intended to be defined by the presence of a generalized capillary endothelial injury. Some patients had post mortem lung biopsies which revealed no evidence of infection or recurrence of haematological malignancies, but revealed diffuse capillary damage and alveolar oedema, with pulmonary fibrosis. The pathogenesis of this syndrome is still unclear. Several cytokines, especially interleukin (IL)-2, have been suspected. CAHILL et al. [22] have suggested that pulmonary endothelial damage may occur during the period of engraftment. This suggestion has been reported by several authors [23-25]. The only two patients without proven infection who survived, received high doses of methylprednisolone. With the use of corticosteroid, and in keeping with empiric antibiotherapy, two cases of "immunologic or idiopathic pneumonia" may have been treated. This rescue therapy with corticosteroids is comparable to the indications of this class of drugs in acute respiratory distress syndrome (ARDS). Corticosteroids can alter the pro-inflammatory responses. Their use in ARDS or sepsis has sporadically led to some favourable outcomes. Several prospective studies have shown no benefit with the use of corticosteroids in the early phase of the disease. Corticosteroids are not recommended in the early phase of ARDS [26-28]. During the fibroproliferative phase of ARDS ( $>1$ week after the onset), MEDURI et al. [29, 30] reported that corticosteroids were useful. This treatment can be used later, i.e. 7-14 days after the onset of ARDS, or when there is no sign of improvement $2-5 \mathrm{mg}$ methylprednisolone. $\mathrm{kg}^{-1}$. day ${ }^{-1}$. The aforementioned authors recommend ruling out systemic or pulmonary infection before the administration of corticosteroids. This recommendation was followed in the present study.

In conclusion, in the early phase of bone marrow transplantation the recipients without a proven aetiology of pneumonia had a worse clinical outcome than grafted patients with proven infectious pneumonia. In order to avoid endotracheal intubation, noninvasive continuous positive airway pressure ventilation was more efficient in neutropenic bone marrow transplant recipients with proven infectious aetiology. An evaluation in order to establish a diagnosis in noninfectious acute respiratory failure after bone marrow transplantation should be carried out in ongoing studies.

Acknowledgements. The authors gratefully thank G. Chene for her help in the statistical analysis and T. Embleton for her invaluable assistance in editing this manuscript.

\section{References}

1. Krowka MJ, Rosenow EC, Hoagland HC. Pulmonary complications of bone marrow transplantation. Chest 1985; 87: 237-246.

2. Cordonnier C, Bernaudin JF, Bierling P, Huet Y, Vernant JP. Pulmonary complications occurring after allogeneic bone marrow transplant. Cancer 1986; 58: 1047-1054. 
3. Campbell JH, Blessing N, Burnett AK, Stevenson RD. Investigation and management of pulmonary infiltrates following bone marrow transplantation: an 8-year review. Thorax 1993; 48: 1248-1251.

4. Meyers JD, Flournoy N, Thomas ED. Non bacterial pneumonia after allogeneic marrow transplantation: a review of ten years' experience. Rev Infect Dis 1982; 4: 11191132.

5. Wingard JR, Mellits ED, Sostrin MB, et al. Interstitial pneumonia after allogeneic marrow transplantation. Medicine (Baltimore) 1988; 67: 175-186.

6. Sloane JP, Depledge MH, Powles RL, Morgenstern GR, Trickey BS, Dady PJ. Histopathology of the lung after bone marrow transplantation. J Clin Pathol 1983; 36: 546-554.

7. Beschorner WE, Saral Et, Hutchin GM, Tutschka PJ, Santos GW. Lymphocytic bronchitis associated with graft versus host disease in recipients of bone marrow transplants. N Engl J Med 1978; 299: 1030-1036.

8. Thomas ED, Storb R, Clift RA, et al. Bone marrow transplantation. N Engl J Med 1975; 292: 895-902.

9. Hilbert G, Gruson D, Portel L, Gbikpi Benissan G, Cardinaud JP. Non-invasive pressure support ventilation in COPD patients with post-extubation hypercapnic respiratory insuffciency. Eur Respir J 1998; 11: 1349-1353.

10. Hilbert G, Gruson D, Gbikpi-Benissan G, Cardinaud JP. Sequential use of noninvasive pressure support ventilation for acute exacerbations of COPD. Intensive Care Med 1997; 23: 955-961.

11. McDonald GB, Sharma P, Matthews DE, Shulman HM, Thomas ED. Venoocclusive disease of the liver after bone marrow transplantation: diagnosis, incidence, and predisposing factors. Hepatology 1984; 4: 116-122.

12. McDonald ED, Hinds MS, Fisher LD, et al. Venoocclusive disease of the liver and multiorgan failure after bone marrow transplantation: a cohort of 355 patients. Ann Intern Med 1993; 118: 255-267.

13. Crawford SW, Haxkman RC, Clark JG. Open lung biopsy diagnosis of diffuse pulmonary infiltrates after marrow transplantation. Chest 1988; 94: 949-953.

14. Springmeyer SC, Silvestri RC, Sale GE, et al. The role of transbronchial biopsy for the diagnosis of diffuse pneumonias in immunocompromised marrow transplant recipients. Am Rev Respir Dis 1982; 126: 763-765.

15. Legall JR, Lemeshow S, Saulnier F. New simplified acute physiology score (SAPS II) based on a European/North American Multicenter Study. JAMA 1993; 270: 29572963.

16. Murray JF, Matthay MA, Luce JM, Flick MR. An expanded definition of the adult resiratory distress syndrome. Am Rev Respir Dis 1988; 138: 720-723.
17. Appelbaum FR, Meyers JD, Fefer A, et al. Nonbactrial nonfungal pneumonia following marrow transplantation in 100 identical twins. Transplantation 1982; 33: 265268.

18. Dunagan DP, Baker AM, Hurd DD, Haponik EF. Bronchoscopic evaluation of pulmonary infiltrates following bone marrow transplantation. Chest 1997; 111: 135-141.

19. Brunet F, Lanore JJ, Dhainaut JF, et al. Is intensive care justified for patients with haematological malignancies? Intensive Care Med 1990; 16: 291-297.

20. Link H, Reinhard U, Walter E, et al. Lung diseases after bone marrow transplantation. Klin Wochenschr 1986; 64: 595-614.

21. Rubenfield GD, Crawford SW. Withdrawing life support from mechanically ventilated recipients of bone marrow transplants: a case for evidence based guidelines. Ann Intern Med 1996; 125: 625-633.

22. Cahill RA, Spitzer TR, Mazumder A. Marrow engraftment and clinical manifestations of capillary leak syndrome. Bone Marrow Transplant 1996; 18: 177-184.

23. Oeda E, Shinohara K, Kamei S, Nomiyama J, Inoue H. Capillary leak syndrome likely the result of granulocyte colony-stimulating factor after high dose chemotherapy. Intern Med 1994; 33: 115-119.

24. Nurnberger W, Willers R, Burdach S, Göbel U. Risk factors for capillary leakage syndrome after bone marrow transplantation. Ann Hematol 1997; 74: 221-224.

25. Funke I, Prümmer O, Schrezenmeier H, et al. Capillary leak syndrome associated with elevated IL-2 serum levels after allogeneic bone marrow transplantation. Ann Hematol 1994; 68: 49-52.

26. Bernard GR, Luce JM, Sprung CL. High dose corticosteroids in patients with adult respiratory distress syndrome. $N$ Engl J Med 1987; 317: 1565-1570.

27. Luce JM, Montgomery AB, Marks JD, Turner J, Metz CA, Murray JF. Ineffectiveness of high dose methylprednisolone in preventing parenchymal lung injury and improving mortality in patients with septic shock. Am Rev Respir Dis 1988; 138: 62-68.

28. Bone RC, Fisher CJ, Clemmer TP, Slotman GJ, Metz CA. Early methylprednisolone treatment for septic syndrome and the adult respiratory distress syndrome. Chest 1987; 92: 1032-1036.

29. Meduri GU, Belenchia JM, Estes RJ, Wunderink RG, El Torky M, Leeper KV. Fibroproliferative phase of ARDS: clinical findings and effects of corticosteroids. Chest 1991; 100: 943-952.

30. Meduri GU, Chinn AJ, Leeper KV. Corticosteroid rescue treatment of progressive fibroproliferation in late ARDS: patterns of response and predictors of outcome. Chest 1994; 105: 1516-1527. 